\title{
Elevated serum triglycerides is the strongest single indicator for the presence of metabolic syndrome in patients with type 2 diabetes Maria Kompoti ${ }^{2}$, Anargiros Mariolis ${ }^{1}$, Alevizos Alevizos*1,2,3, Ioannis Kyriazis ${ }^{2}$, Ioannis Protopsaltis ${ }^{2}$, Eleni Dimou ${ }^{2}$, Ioannis Lentzas ${ }^{1,2}$, Dimitrios Levisianou ${ }^{2}$, Afroditi Gova ${ }^{2}$ and Andreas Melidonis ${ }^{2}$
}

\author{
Address: ${ }^{1}$ Department of General Practice/Family Medicine, Health Centre of Vyronas, Athens, Greece, ${ }^{2}$ Diabetes Center, Tzanion General \\ Hospital, Piraeus, Greece and ${ }^{3} 3$ korytsas str., 16231 Vyronas, Athens, Greece \\ Email: Maria Kompoti - info@hcvyrona.gr; Anargiros Mariolis - anargirosm@yahoo.gr; Alevizos Alevizos* - alevisos@gmail.com; \\ Ioannis Kyriazis - tzaniodiabetes@yahoo.com; Ioannis Protopsaltis - lentzdoc@yahoo.gr; Eleni Dimou - alvise@tellas.gr; \\ Ioannis Lentzas - lentzdoc@hotmail.com; Dimitrios Levisianou - tzaniodiabetes@yahoo.com; Afroditi Gova - alvise@tellas.gr; \\ Andreas Melidonis - tzaniodiabetes@yahoo.com \\ * Corresponding author
}

Published: 04 October 2006

Cardiovascular Diabetology 2006, 5:21 doi:10.1 186/1475-2840-5-21

This article is available from: http://www.cardiab.com/content/5/I/2 I

(c) 2006 Mariolis et al; licensee BioMed Central Ltd.

This is an Open Access article distributed under the terms of the Creative Commons Attribution License (http://creativecommons.org/licenses/by/2.0), which permits unrestricted use, distribution, and reproduction in any medium, provided the original work is properly cited.
Received: 13 July 2006

Accepted: 04 October 2006

\begin{abstract}
Background: Patients with diabetes already fulfill one diagnostic criterion for MS according to the existing classifications. Our aim was to identify one single clinical parameter, which could effectively predict the presence of MS in patients with type 2 diabetes.
\end{abstract}

Methods: We studied all patients with type 2 diabetes who attended our Diabetes Outpatient Clinic during a three-month period. Waist circumference, blood pressure and serum lipids were measured. Establishment of MS diagnosis was based a) on National Cholesterol Education Program Adult Treatment Panel III (NCEP ATP III) criteria and b) on International Diabetes Federation (IDF) criteria. Receiver operating characteristic (ROC) analysis was applied in order to identify the clinical parameter with the highest predictive capability for MS. Among the 500 participating patients (23I males, 269 females), MS was diagnosed in 364 patients $(72.8 \%$ ) according to the NCEP ATP III criteria and in 408 patients (81.6\%) according to the IDF criteria.

Results: For the NCEP ATP III classification, serum triglycerides (in the overall population), waist and HDL (in female population) demonstrated the highest predictive capability for MS (AUCs:0.786, 0.805 and $0.80 \mathrm{I}$, respectively). For the IDF classification, no single parameter reached an AUC > 0.800 in the overall population. In females, HDL displayed a satisfactory predictive capability for MS with an AUC which was significantly higher than the one in males $(0.785 \mathrm{vs.} 0.676$, respectively, $\mathrm{P}<0.05$ ).

Conclusion: Elevated serum triglycerides strongly indicate the presence of MS in patients with type 2 diabetes. In female patients with type 2 diabetes, central obesity was the second stronger predictor of MS besides hypertriglyceridemia. 


\section{Background}

Patients with the metabolic syndrome (MS) are at increased risk of coronary heart disease and other cardiovascular diseases related to plaque buildups in artery walls (e.g., stroke and peripheral vascular disease) [1]. Moreover MS also increases mortality from both cardiovascular disease and all causes [2,3]. Patients with type 2 diabetes already fulfill one of the NCEP ATP III or IDF diagnostic criteria, while at least two more are required for the confirmation of NCEP ATP III/M.S diagnosis, and necessarily abdominal obesity plus one additional criterion for the IDF/MS diagnosis $[4,5]$. Several studies have investigated the role of each of the metabolic syndrome components in modifying cardiovascular risk in patients with type 2 diabetes [6].

Our study aimed in identifying a single parameter - of those used for diagnosing MS according to NCEP ATP III and IDF classifications - which could predict the presence of the syndrome in patients with type 2 diabetes.

\section{Research design and methods}

We studied all patients with type 2 diabetes who attended our Diabetes Outpatient Clinic during a three-month period in 2004. Pregnant females were excluded from the study. Waist circumference, systolic (SBP) and diastolic (DBP) blood pressure were measured, body mass index (BMI) was estimated and blood samples were drawn for serum lipids measurement after a 12-hour fast. Establishment of MS diagnosis was based: a) on NCEP ATP III criteria [4] and b) on IDF criteria [5]. The study was approved by the ethical review committee of our hospital. All patients gave an informed consent.

According to the NCEP ATP III classification, MS is defined as the presence of three or more of the following criteria: 1) increased waist circumference $(>102 \mathrm{~cm}$ in males, $>88 \mathrm{~cm}$ in females), 2) elevated serum triglycerides $(\geq 150 \mathrm{mg} / \mathrm{dl})$, 3) low HDL cholesterol $(<40 \mathrm{mg} / \mathrm{dl}$ in males, $<50 \mathrm{mg} / \mathrm{dl}$ in females), 4) hypertension (SBP $\geq 130$ $\mathrm{mmHg}$ and/or DBP $\geq 85 \mathrm{mmHg}$ ) or medical treatment of previously diagnosed hypertension and 5) impaired fasting glucose ( $\geq 110 \mathrm{mg} / \mathrm{dl})$. According to the new IDF definition, diagnosis of MS requires central obesity (defined as waist circumference $\geq 94 \mathrm{~cm}$ for Europid men and $\geq 80 \mathrm{~cm}$ for Europid women, with ethnicity specific values for other groups) plus any two of the following: 1) elevated serum triglycerides $(\geq 150 \mathrm{mg} / \mathrm{dl})$ or specific treatment for this lipid abnormality, 2) low HDL cholesterol (<40 mg/ $\mathrm{dl}$ in males, $<50 \mathrm{mg} / \mathrm{dl}$ in females) or specific treatment for this lipid abnormality, 3) hypertension (SBP $\geq 130$ $\mathrm{mmHg}$ and/or DBP $\geq 85 \mathrm{mmHg}$ ) or medical treatment for previously diagnosed hypertension and 4) high fasting plasma glucose $(\geq 100 \mathrm{mg} / \mathrm{dl})$ or previously diagnosed type 2 diabetes.
We created receiver operating characteristics (ROC) curves of serum triglycerides, HDL, SBP, DBP and waist circumference for the prediction of MS and we used the areas under the corresponding curves (area under the curve, AUC) to evaluate the predictive efficiency of each MS parameter. Statistical analysis was performed with SPSS 10.0 (1999, Chicago, IL). Statistical significance was set at a level of $p<0.05$. Variables with AUCs $\geq 0.800$ were considered as having satisfactory predictive capability for the presence of MS. We used the algorithms of Hanley and McNeil for comparison of AUCs derived from different samples [7] or from the same sample [8]. The critical level for the $\mathrm{z}$ statistic was set at 1.96. We also tried different cutoffs in the selected variables and estimated the corresponding sensitivity (SENS), specificity (SPEC), positive predictive value (PPV) and negative predictive value (NPV). Serum HDL and waist circumference were analyzed according to gender, since the cutoffs used in the two definitions for these variables are different in males and females.

\section{Results}

500 patients (231 males and 269 females) were enrolled in the study. Metabolic syndrome was diagnosed in 364 patients $(72.8 \%)$ according to the NCEP ATP III criteria and in 408 patients (81.6\%) according to the IDF criteria. The concordance between the two classifications was moderate $(\mathrm{kappa}=0.640, \mathrm{p}<0.001) .10$ (2.7\%) of the 364 patients diagnosed with MS according to the NCEP ATP III classification did not fulfill the IDF criteria for MS, while 54 (13.2\%) of the 408 patients diagnosed with MS according to the IDF classification did not fulfill the NCEP ATP III criteria for MS. After stratification by gender, 213 females (79.1\%) and 151 males (65.4\%) had MS according to the NCEP ATP III classification ( $\mathrm{p}=0.001)$, while 232 females $(86.2 \%)$ and 176 males (76.2\%) had MS according to the IDF classification ( $p=0.004)$. Demographic and other characteristics of the patients with MS vs. those without MS according to the two classifications are shown in table 1.

For the NCEP ATP III classification, serum triglycerides in the overall population, and waist circumference and HDL in females had the highest predictive ability for MS (AUCs: $0.786,0.805$ and 0.801 , respectively). After stratification by gender, the AUC for triglycerides differed significantly ( 0.843 in females vs. 0.744 in males, $z=2.47, p$ $<0.05)$. In younger patients $(<50$ years old), AUC for serum triglycerides was 0.811 [95\% confidence intervals (CI) $0.685-0.939, \mathrm{p}<0.001]$. In females, serum triglyceride level was a stronger predictor of MS than waist circumference ( 0.843 vs. 0.805 , respectively), but the difference did not reach statistical significance $(z=0.82, p=N S)$. 
Table I: Demographic, clinical and laboratory data of the patients

\begin{tabular}{|c|c|c|c|c|c|c|}
\hline \multirow[t]{2}{*}{ Variable } & \multicolumn{3}{|c|}{ MS according to NCEP-ATP III criteria } & \multicolumn{3}{|c|}{ MS according to IDF criteria } \\
\hline & With MS $(n=364)$ & Without MS $(n=136)$ & p value & With MS $(n=419)$ & Without MS $(n=8 I)$ & $\mathrm{p}$ value \\
\hline Age (years)* & $65.9 \pm 10.0$ & $62.0 \pm 12.9$ & 0.002 & $65.6 \pm 10.2$ & $61.6 \pm 13.6$ & 0.010 \\
\hline $\begin{array}{c}\text { Diabetes duration } \\
\text { (years) }\end{array}$ & $12.7 \pm 8.4$ & $11.5 \pm 8.5$ & 0.166 & $12.5 \pm 8.3$ & $11.7 \pm 8.9$ & 0.389 \\
\hline BMI $\left(\mathrm{kg} / \mathrm{m}^{2}\right)$ & $30.0 \pm 5.2$ & $26.7 \pm 4.3$ & $<0.001$ & $29.9 \pm 5.0$ & $25.9 \pm 4.8$ & $<0.001$ \\
\hline Waist $(\mathrm{cm})$ males & $108 \pm 11$ & $98 \pm 9$ & $<0.001$ & $107 \pm 10$ & $95 \pm 11$ & $<0.001$ \\
\hline Waist (cm) females & $105 \pm 9$ & $89 \pm 17$ & $<0.001$ & $104 \pm 10$ & $89 \pm 20$ & $<0.001$ \\
\hline $\begin{array}{c}\text { Serum HDL }(\mathrm{mg} / \mathrm{d}) \\
\text { males }\end{array}$ & $42 \pm 10$ & $51 \pm 11$ & $<0.001$ & $44 \pm 11$ & $51 \pm 12$ & $<0.001$ \\
\hline $\begin{array}{c}\text { Serum HDL }(m g / d l) \\
\text { females }\end{array}$ & $49 \pm 10$ & $61 \pm 10$ & $<0.001$ & $50 \pm 11$ & $61 \pm 10$ & $<0.001$ \\
\hline $\begin{array}{c}\text { Serum triglycerides } \\
(\mathbf{m g} / \mathrm{dl})\end{array}$ & $|72 \pm 9|$ & $106 \pm 50$ & $<0.001$ & $164 \pm 90$ & $111 \pm 57$ & $<0.001$ \\
\hline SBP $(\mathbf{m m H g})$ & $134 \pm 19$ & $126 \pm 14$ & $<0.001$ & $134 \pm 19$ & $123 \pm 11$ & $<0.001$ \\
\hline DBP (mmHg) & $79 \pm 11$ & $75 \pm 8$ & $<0.001$ & $79 \pm 11$ & $74 \pm 6$ & $<0.001$ \\
\hline $\begin{array}{c}\text { Glycosylated } \\
\text { hemoglobin (\%) }\end{array}$ & $7.1 \pm 1.3$ & $7.0 \pm 1.3$ & 0.137 & $7.1 \pm 1.3$ & $7.0 \pm 1.3$ & 0.416 \\
\hline
\end{tabular}

We have calculated SENS, SPEC, PPV, and NPV at different cutoffs for triglycerides (in the overall population) and for waist and HDL in females, to assess the specificity for MS diagnosis according to the NCEP ATP III classification (Table 2). We aimed at cutoffs with satisfactory specificity $(\geq 70 \%)$ for MS diagnosis [9], but with a reasonably acceptable sensitivity $(>60 \%)$ as well. The estimated PPVs were high, while the NPVs were low, as expected from the high prevalence of the syndrome in our patient population. A cutoff of $120 \mathrm{mg} / \mathrm{dl}$ for serum triglycerides showed a satisfactory SPEC (70\%), while a higher cutoff of $140 \mathrm{mg} / \mathrm{dl}$ had an even higher SPEC (88\%). Serum HDL cutoffs of 55 and $50 \mathrm{mg} / \mathrm{dl}$ showed SPEC (66\% and 93\%, respectively). A waist cutoff of 98 $\mathrm{cm}$ in females showed $72 \%$ SPEC and a higher cutoff of $100 \mathrm{~cm}$ had similar SPEC (75\%). In the majority (73.3\%) of females with waist $>98 \mathrm{~cm}$, hypertension was the criterion which accomplished the MS diagnosis, while in nearly all females with HDL $<50 \mathrm{mg} / \mathrm{dl}$ or triglycerides $>150 \mathrm{mg} / \mathrm{dl}$ (97.3\% and $98.0 \%$, respectively), MS diagnosis was accomplished by the waist criterion.

For the IDF classification, in the overall population, no single parameter reached an $A U C \geq 0.800$. In females, serum HDL displayed the highest predictive capability for MS with an AUC which was significantly higher than the one in males $(0.785$ vs. 0.676 , respectively, $\mathrm{p}<0.05)$. However, HDL cutoffs above the suggested $50 \mathrm{mg} / \mathrm{dl}$ cutoff in females exhibited SPEC lower than 70\% (table 3).

The AUC for triglycerides was higher in females compared to males (0.803 vs. 0.719), as with the NCEP ATP III classification, but the observed difference did not reach statis- tical significance. However, serum triglycerides above the $150 \mathrm{mg} / \mathrm{dl}$ cutoff in the overall population and HDL below the $50 \mathrm{mg} / \mathrm{dl}$ cutoff in females had 100\% SPEC and $100 \%$ PPV, since patients with diabetes, central obesity (a prerequisite risk factor for IDF MS) plus one lipid criterion fulfill three IDF criteria.

\section{Discussion}

Patients with type 2 diabetes have higher cardiovascular risk than non-diabetic subjects, independently of other risk factors such as smoking, hypertension or hypercholesterolemia [10]. Moreover, the prevalence of coronary heart disease in diabetic patients increases significantly with the addition of MS components [6].

Prevalence of MS in patients with type 2 diabetes is considerably high $(70-92 \%)$, as reported by several studies using either NCEP ATP III or World Health Organization (WHO) criteria $[6,11-15]$. In our patient population, the estimated prevalence of MS was similarly high as expected (72.8\% based on the NCEP ATP III criteria and $81.6 \%$ based on the IDF criteria).

The identification of patients with MS among patients with type 2 diabetes is of great importance, since this population carries a cluster of cardiovascular risk factors and should be urged to show major compliance to their therapeutic regimen. The recognition of a single parameter with high efficiency in predicting MS in patients with type 2 diabetes was the primary aim of our study. ROC curves are commonly adopted in order to determine the predictive ability of various methods or parameters used for the 
Table 2: Triglyceride, HDL and waiste circumference cutoffs and respective sensitivity and specificity of MS diagnosis according to NCEP-ATP III and IDF classifications.

\begin{tabular}{|c|c|c|c|c|c|c|c|c|}
\hline \multirow{2}{*}{$\begin{array}{c}\text { Cutoffs } \\
\text { TGC (mg/dl) }\end{array}$} & \multicolumn{4}{|c|}{ NCEP-ATP III } & \multicolumn{4}{|c|}{ IDF } \\
\hline & SENS (\%) & SPEC (\%) & PPV (\%) & NPV (\%) & SENS (\%) & SPEC (\%) & PPV (\%) & NPV (\%) \\
\hline 120 & 70 & 70 & 85 & 47 & 67 & 66 & 89 & 31 \\
\hline 130 & 66 & 77 & 88 & 46 & 60 & 71 & 90 & 29 \\
\hline 140 & 61 & 88 & 92 & 46 & 55 & 81 & 93 & 29 \\
\hline 150 & 53 & 92 & 95 & 42 & 47 & $100 *$ & $100 *$ & 21 \\
\hline HDL (mg/dl) Females & SENS (\%) & SPEC (\%) & PPV (\%) & NPV (\%) & SENS (\%) & SPEC (\%) & PPV (\%) & NPV (\%) \\
\hline 50 & 53 & 93 & 93 & 34 & 49 & $100 *$ & $100 *$ & 20 \\
\hline 55 & 71 & 66 & 89 & 38 & 67 & 62 & 92 & 29 \\
\hline 60 & 87 & 48 & 86 & 50 & 84 & 31 & 90 & 31 \\
\hline Waist (cm) Females & SENS (\%) & SPEC (\%) & PPV (\%) & NPV (\%) & SENS (\%) & SPEC (\%) & PPV (\%) & NPV (\%) \\
\hline 90 & 97 & 52 & 88 & 82 & & & & \\
\hline 95 & 83 & 67 & 90 & 55 & & & & \\
\hline 98 & 79 & 72 & 90 & 41 & & ** & & \\
\hline 100 & 71 & 75 & 90 & 41 & & & & \\
\hline 102 & 57 & 77 & 90 & 32 & & & & \\
\hline
\end{tabular}

*Patients fulfill three IDF criteria.

**No AUCs calculated, because central obesity is a prerequisite for MS diagnosis with IDF criteria.

confirmation of a disease, a clinical characteristic or an outcome.

In the overall population, serum triglycerides had a satisfactory predictive ability for NCEP ATP III MS, while for the IDF classification, no single parameter reached an AUC $\geq 0.800$. Serum triglycerides in females displayed the highest AUCs in both classifications. The predictive ability of triglycerides for the NCEP ATP III MS was higher in females compared to males, while for the IDF MS a similar difference did not reach statistical significance. Serum HDL proved to be useful in females for both classifications, but its predictive ability in males was not satisfactory. A serum HDL lower than $50 \mathrm{mg} / \mathrm{dl}$ in females with diabetes (HDL criterion fulfilled) predicted the presence of the whole syndrome with a specificity of $92 \%$.

Furthermore, measurement of waist circumference although easily performed in every clinical setting (hospital, outpatient clinic, home), proved to be more useful in females than in males. A waist circumference of $98 \mathrm{~cm}$ in females with diabetes has been proved sufficient in predicting the presence of MS according to the NCEP ATP III classification.

\section{Limitations}

There were several limitations in our study. The population sample was not so large as to yield statistically significant results for small differences between AUCs [7]. In particular, differences between clinical parameters in the same set of patients (e.g. serum triglycerides vs. waist circumference in females) should be tested with larger sam- ples to minimize the possibility of type II error. In addition, our population sample was a selected one, since it consisted of patients who were regularly followed up in an outpatient clinic. It would be interesting to apply the same method in patients with recently diagnosed diabetes or in patients with incidentally diagnosed diabetes from a random population sample.

Nevertheless, the information retrieved from our study implies that a female with type 2 diabetes and central obesity most probably has the entire MS according to the NCEP ATP III classification.

\section{Conclusion}

Elevated serum triglyceride level was the strongest single predictor which effectively indicated the presence of MS in both male and female patients with type 2 diabetes according to the NCEP ATP III classification. In female patients with type 2 diabetes, central obesity as implied by an increased waist circumference was the second stronger predictor of MS after hypertriglyceridemia.

\section{References}

I. Isomaa B, Almgren P, Tuomi T, Forsen B, Lahti K, Nissen M, taskinen MR, Groop L: Cardiovascular mortality and mortality associated with the metabolic syndrome. Diabetes Care 200I, 24:683-689.

2. Haffner SM: The metabolic syndrome: inflammation, diabetes mellitus, and cardiovascular disease. Am J Cardiol 2006, 97(2A):3A-IIA.

3. Lorenzo C, Williams K, Hunt KJ, Haffner SM: Trend in the prevalence of the metabolic syndrome and its impact on cardiovascular disease incidence: the San Antonio Heart Study. Diabetes Care 2006, 29(3):625-30.

4. Expert Panel on Detection, Evaluation, and Treatment of High Blood Cholesterol in Adults: Executive Summary of the 
Third Report of the National Cholesterol Education Program (NCEP) Expert Panel on Detection, Evaluation, and Treatment of High Blood Cholesterol in Adults (Adult Treatment Panel III). JAMA 200I, 288:2486-2497.

5. Alberti G: Introduction to the metabolic syndrome. Eur Heart J 2005, 7(Suppl D):3-5.

6. Alexander CM, Landsman PB, Teutsch SM, Haffner SM: NCEPdefined metabolic syndrome, diabetes, and prevalence of coronary heart disease among NHANES III participants age 50 years and older. Diabetes 2003, 52:1210-12/4.

7. Hanley JA, McNeil BJ: The meaning and use of the area under a receiver operating characteristic (ROC) curve. Radiology 1982, 143:29-36.

8. Hanley JA, MCNeil BJ: A method of comparing the areas under receiver operating characteristic curves derived from the same cases. Radiology 1983, 148:839-843.

9. Sackett DL, Hayes RB, Guyatt GH, Tugwell P: The interpretation of diagnostic data (Ch. 4). In Clinical Epidemiology: A Basic Science for Clinical Medicine 2nd edition. Little, Brown and Company, Boston MA; 1991:69-152.

10. Stamler J, Vaccaro O, Neaton JD, Wentworth D: Diabetes, other risk factors, and 12-year cardiovascular mortality for men screened in the Multiple Risk Factor Intervention Trial (MRFIT). Diabetes Care 1993, 16:434-444.

11. World Health Organization: Definition, Diagnosis and Classification of Diabetes Mellitus and its Complications. Part I: Diagnosis and Classification of Diabetes Mellitus. Geneva, World Health Org; 1999.

12. Ford ES, Giles WH: A comparison of the prevalence of the metabolic syndrome using two proposed definitions. Diabetes Care 2003, 52:2740-2747.

13. Meigs JB, Wilson PWF, Nathan DM, D'Agostino RB, Williams K, Haffner SM: Prevalence and characteristics of the metabolic syndrome in the San Antonio Heart and Framingham Offspring studies. Diabetes 2003, 52:2160-2167.

14. Bruno G, Merletti F, Biggeri A, Bargero G, Ferrero S, Runzo C, Prina Cerai S, Pagano G, Cavallo-Perin P: Casale Monferrato Study. Metabolic syndrome as a predictor of all-cause and cardiovascular mortality in type 2 diabetes: the Casale Monferrato Study. Diabetes Care 2004, 27:2689-2694.

15. Bonora E, Targher G, Formentini G, Calcaterra F, Lombardi S, Marini P, Zenari L, Saggiani F, Poli M, Perbellini S, Raffaelli A, Gemma L, Santi $\mathrm{L}$, Bonadonna RC, Muggeo M: The metabolic syndrome is an independent predictor of cardiovascular disease in type 2 diabetic subjects. Prospective data from the Verona Diabetes Complications Study. Diabet Med 2004, 21:52-58.

\section{Publish with Bio Med Central and every scientist can read your work free of charge}

"BioMed Central will be the most significant development for disseminating the results of biomedical research in our lifetime. "

Sir Paul Nurse, Cancer Research UK

Your research papers will be:

- available free of charge to the entire biomedical community

- peer reviewed and published immediately upon acceptance

- cited in PubMed and archived on PubMed Central

- yours - you keep the copyright
BioMedcentral 